\title{
Developmental ossification sequences of the appendicular and axial skeleton in Kuttanad duck embryos (Anas platyrhynchos domesticus)
}

\author{
A.D. Firdous ${ }^{1, *}$, S. Maya ${ }^{2}$, K. Massarat ${ }^{1}$ and M.A. Baba ${ }^{1}$ \\ ${ }^{1}$ Division of Veterinary Anatomy and Histology, FVSC \& AH Shuhama Alusteng Jammu and Kashmir, India \\ ${ }^{2}$ Department of Veterinary Anatomy and Histology, CV\& AS, Mannuthy, Kerala, India
}

\begin{abstract}
The processes of ossification sequences are poorly investigated for birds in general, even for domestic and experimental species and when it comes to the waterfowl it is almost negligible. Such sequences constitute a rich source of data on character evolution, and may even provide phylogenetic information. A pre-hatch developmental study on ossification sequences of axial and appendicular skeletal system in Kuttanad duck embryos was undertaken using 78 viable embryos. From day 3 to day 7 of incubation no ossification densities were seen both by alizarin red staining and computerized radiography. The first indication of ossification as small ossification centers in skull bones, clavicle, scapula, humerus, radius and ulna in forelimb and ilium, pubis femur and fibula in hind limb were observed on the $9^{\text {th }}$ day of incubation. The ossification of the body of the ribs started at the $11^{\text {th }}$ day of incubation towards the proximal extremity. On day $13^{\text {th }}$ the ossification process of vertebrae was started from cervical end. The variation in appearance of the ossification centers in different bones at different stages of incubation period suggests relative importance of phylogeny to the sequences.
\end{abstract}

Keywords: Alizarin red, Duck, Ossification, Radiography.

\section{Introduction}

It is poorly understood or still in infancy, what factors influence ossification sequences and what the relative importance of phylogeny is to the sequences. Galliformes are among domestic birds that could be considered as a good model to examine these variables. Waterfowl comes second to the Galliformes and will substitute the domestic fowl in many ways as an experimental valuable model for studying the vertebrate skeletal defects. These birds are osteologically conservative, have precocial young, but have a broad spectrum of body sizes and incubation periods. Birds are said to show the least embryonic variation of all groups of vertebrates (Kerr, 1919; Richardson et al., 1997). It has been argued that specific differences between birds arise largely through modifications at later stages of development (Ricklefs and Starck, 1998). Patterns of early embryonic development have traditionally been viewed as invariant within vertebrate taxa. The passive components of avian skeletal system i.e. bone development and health is an important subject in avian research, because of its significance in the poultry industry. Many of the pathological skeletal deformities are still common and do not appear to be linked to define causes e.g. varus and valgus deformation of the long bones are examples. Although there are dissimilarities between human and avian bone development, the avian is considered as a valuable model for human skeletal defects (Cook, 2000). Though a lot of work has been done on the developmental aspects of the skeletal system in birds; research on skeletal system development waterfowl is scanty. Hence the aim of this study was to investigate the developmental way of the passive part of the skeletal system of Kuttanad duck embryos that will add the knowledge in the anatomical literature and will help the allied subjects on comparative basis.

\section{Materials and Methods}

The material of this study consisted of 78 Kuttanad duck's viable embryos, collected from $3^{\text {rd }}$ to $28^{\text {th }}$ day of incubation procured from the University Poultry and Duck Farm, Mannuthy, Thrissur Kerala, India. The number of viable embryos collected in a given period of incubation is shown in Table 1 (6 embryos at each time point). The eggs were incubated at $37-38.9^{\circ} \mathrm{C}$ with humidity of $30-35 \%$. The eggs were rotated at least three times a day, half turn each rotation. Starting from $3^{\text {rd }}$ day of incubation, six eggs with viable embryos were collected. At day $25^{\text {th }}$ the incubation temperature was decreased to $36-37^{\circ} \mathrm{C}$ and the humidity was increased to $70 \%$.

\section{Techniques to access the sequence of ossification} Toluidine Blue-Alizarin Red S Staining of Cartilage and Bone protocol (Burdi, 1965)

Cartilage and bone were differentiated in whole-mount preparations with toluidine blue-alizarin red $\mathrm{S}$ staining after formalin, acetic acid and alcohol (FAA) fixation. Specimens were fixed in FAA solution having the ratio of three components as 1:1:8 for approximately 40 minutes. Then they were stained in $0.06 \%$ toluidine blue made in $70 \%$ ethyl alcohol for 48 hours at room temperature. 
Table 1. Number of viable embryos collected at different days of incubation.

\begin{tabular}{|c|c|c|c|c|c|c|c|c|c|c|c|c|c|}
\hline Incubation period (days) & $3^{r d}$ & $5^{\text {th }}$ & $7^{\text {th }}$ & $9^{\text {th }}$ & $11^{\text {th }}$ & $13^{\text {th }}$ & $15^{\text {th }}$ & $17^{\text {th }}$ & $19^{\text {th }}$ & $21^{s t}$ & $23^{r d}$ & $25^{\text {th }}$ & $27^{\text {th }}$ \\
\hline Number of embryos collected & 6 & 6 & 6 & 6 & 6 & 6 & 6 & 6 & 6 & 6 & 6 & 6 & 6 \\
\hline
\end{tabular}

Twenty volumes of stain solution to the estimated volume of the specimen were used. Soft tissues were destained in $35 \%$ ethyl alcohol for 20 hours; $5 \%$ for 28 hours and $70 \%$ for 8 hours respectively. The specimens were counterstained in a freshly prepared $1 \%$ aqueous solution of $\mathrm{KOH}$ to which $2-3$ drops of $0.1 \%$ alizarin red $\mathrm{S}$ per $100 \mathrm{ml}$ of solution was added. The specimens were transferred into the fresh $1 \% \mathrm{KOH}$-alizarin mixture daily for 3 days, or until the bones had reached the desired intensity of red and soft tissues. The specimens were rinsed in water, placed in a 1:1 mixture of glycerol and ethyl alcohol for 1-2 hours and then transferred into fresh glycerol-alcohol for final clearing and storage.

\section{Radiography}

Ex ovo radiographs of the skeletal system were taken at different ages to reach the extent of ossification and development of various components of this system. Radiographs were taken by computerized digital radiography equipment, which was provided by Department of Veterinary Surgery and Radiology, College of Veterinary and Animal sciences, Mannuthy.

\section{Stereozoom microscopy}

The embryos were viewed by stereozoom microscope, which was provided by Department of Veterinary Physiology and Department of Veterinary Parasitology.

\section{Results}

No ossification centers were seen from the $3^{\text {rd }}$ to the $7^{\text {th }}$ day of incubation. Both alizarin red staining and computerized radiography could not detect any ossification densities (Fig. 1). The degree of ossification during different stages of incubation period in Kuttanad duck was efficiently visualized by computerized radiography (Fig. 2, 3 and 4). For convenience of description, the skeleton was divided into four parts, viz., skull, vertebrae, ribs and sternum and forelimb and hind limb. In earlier stages of the embryonic life in Kuttanad ducks most elements of the skull were still separated. By 27 days of incubation facial bones were largely fused but the skull was still opened dorsally. The bones of the skull from $3^{\text {rd }}$ day of incubation till $7^{\text {th }}$ day did not stain with alizarin red. The first indication of ossification in skull bones as a small ossification centers were observed in squamosal bone on $9^{\text {th }}$ day of incubation (Fig. 5 and 6). The process of ossification was followed by palatine, pterygoid, prefrontal, and the bones forming the beak such as maxilla, jugal, quadratojugal, splenial, angular, supraangular and premaxilla. The last bones to be ossified were the frontal and nasal bones and by $13^{\text {th }}$ day all skull bones appeared and were maximally ossified (Fig. 7). The red regions of each skull bone were enlarged with the advancement of incubation period.

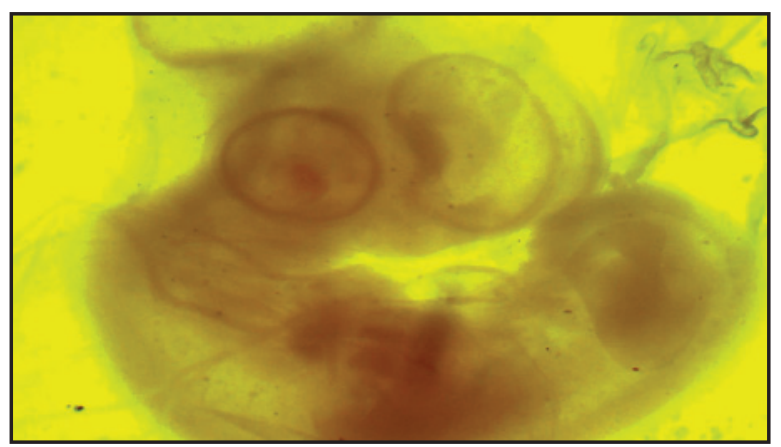

Fig. 1. $5^{\text {th }}$ day of incubation of Kuttanad duck embryo without any signs of ossification. Alizarin red staining.

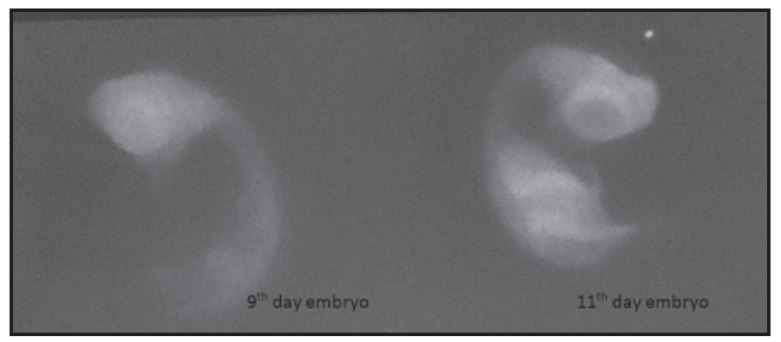

Fig. 2. Digital radiograph of Kuttanad duck embryos.

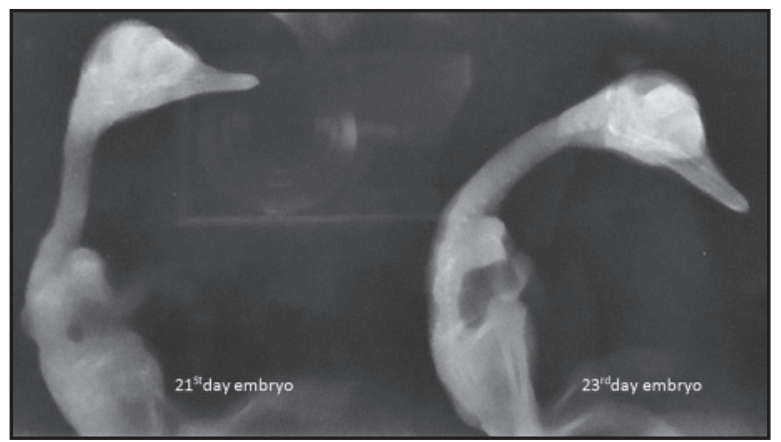

Fig. 3. Digital radiograph of Kuttanad duck embryos showing ossification centers in different bones.

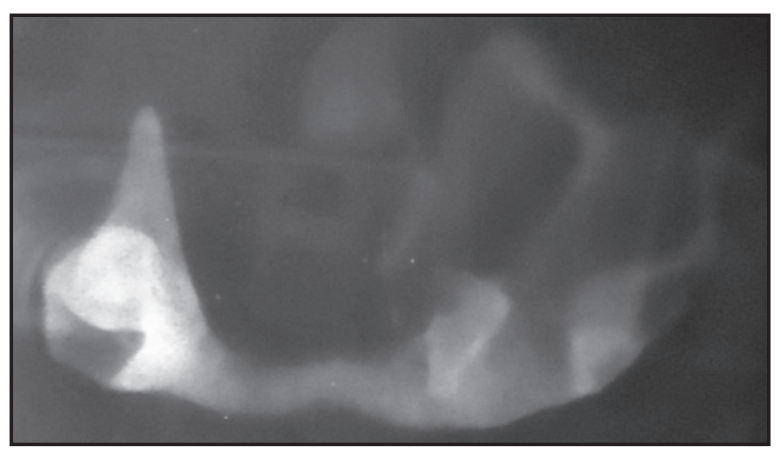

Fig. 4. Digital radiograph of $25^{\text {th }}$ day old Kuttanad duck embryo showing ossification centers. 
The long bones in the post cranial part of the skeleton in the Kuttanad duck were the first to show the process of mineralization. The fore and hind limbs showed endochondral calcification and the ossification process started at the center of the diaphysis and extended towards the epiphysis. On the $9^{\text {th }}$ day of incubation small ossification centers were observed in clavicle, scapula, humerus, radius and ulna in forelimb and ilium, pubis femur and fibula in hind limb (Fig. 8). By day 11 of incubation the size of the ossification centers got

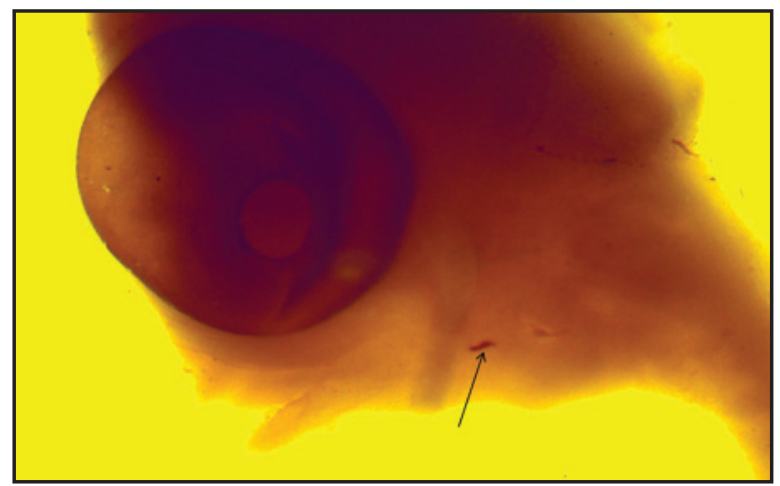

Fig. 5. First indication of ossification in skull at $9^{\text {th }}$ day of incubation (arrow). Alizarin red staining.

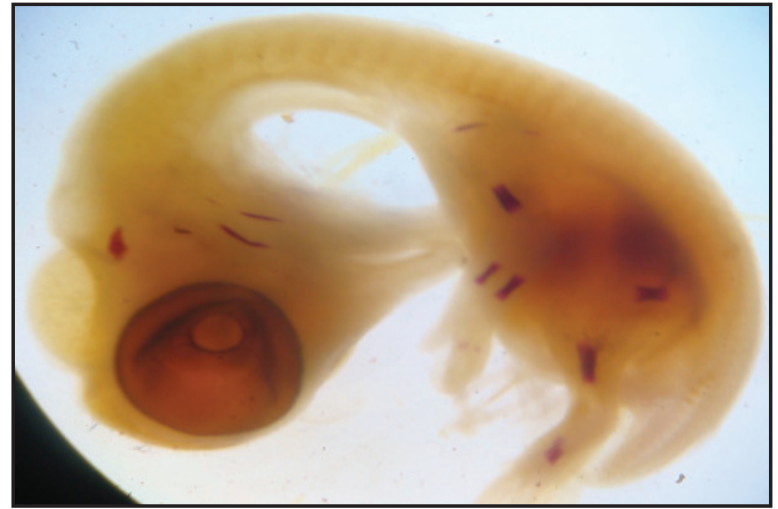

Fig. 6. Ossification centers in skull bones at $11^{\text {th }}$ day of incubation in Kuttanad duck embryo. Alizarin red staining.

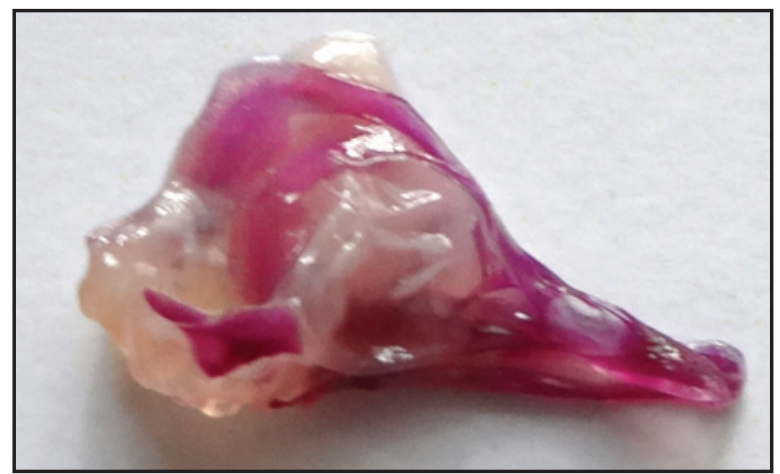

Fig. 7. Maximally ossified $13^{\text {th }}$ day incubated skull bones of Kuttanad duck embryo. Alizarin red staining. increased. On day $13^{\text {th }}$ of incubation new ossification centers were observed on radius, ulna, carpometacarpal joint, ulnar carpal, metatarsus, tibiotarsus, first phalanx of digit ii and second phalanx of digit iii. Day 15 marked the ossification centers on digit ii, iii, iv of forelimb and additional ossification centers were observed in $1^{\text {st }}, 2^{\text {nd }}$, $3^{\text {rd }}$ phalanx of digit iii and $4^{\text {th }}$ phalanx of digit ii of pelvic limb. Between days 17 and 19 of incubation there were prominent and clear increase of ossification centers in both limbs (Fig. 9). Right and left clavicles showed the process of ossification on the $9^{\text {th }}$ day but were not fused. Both clavicles were joined on $23^{\text {rd }}$ day of incubation but not properly fused. On $28^{\text {th }}$ day of developmental process the growth plates of long bones were still open. On $17^{\text {th }}$ day of incubation the vertebral arches of all the cervical, thoracic, lumbar and sacral vertebrates showed ossification (Fig. 10 and 11). On day $21^{\text {st }}$ of incubation ossification was seen on pygostyle. The calcification of

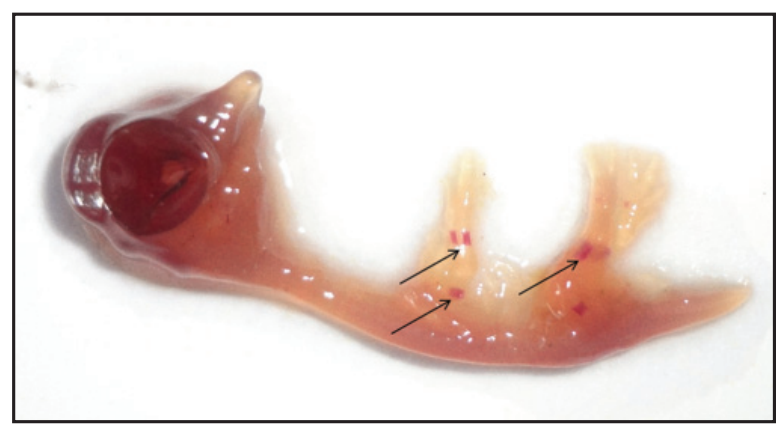

Fig. 8. Ossification centers (arrows) appeared in long bones on $9^{\text {th }}$ day of incubation.Alizarin red staining.

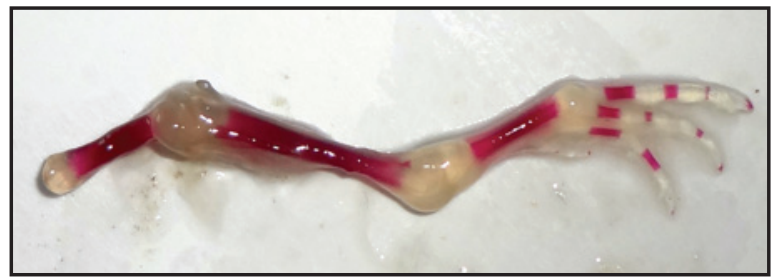

Fig. 9. Prominent ossification centers at $19^{\text {th }}$ day of incubation in hind limb. Alizarin red staining.

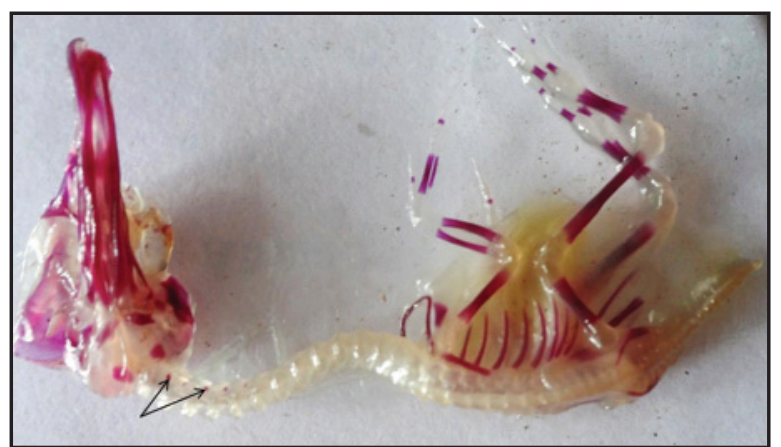

Fig. 10. Ossification centers of vertebrae at cervical end (arrows). Alizarin red staining. 
the body of the ribs started at the $11^{\text {th }}$ day of incubation towards the proximal extremity (Fig. 12). In both vertebral and sternal ribs, ossification first occurred at the middle region and then progressed towards the proximal and distal regions. As the ossification extended in both ways an area towards the vertebra remained cartilaginous till hatching. The uncinate process of the rib first appeared as cartilage then it was calcified. In Kuttanad ducks the keel bone began to ossify firstly towards the caudal side and then cranially. The ossification of the Axial and Appendicular bones in a given incubation period is shown in Table 2 .

\section{Discussion}

A detailed description of skeletogenesis and ossification sequence for the chicken and Japanese quail has been provided by many researchers (Rogulska, 1962; Hogg, 1980; Nakane and Tsudzuki, 1999). The ossification sequence of the Kuttanad duck variety has not previously been described. This study besides describing the process of ossification in Kuttanad duck may also reveal the relative importance of egg size and incubation period to ossification sequence in this species. The relative sequence of ossification was the same whether

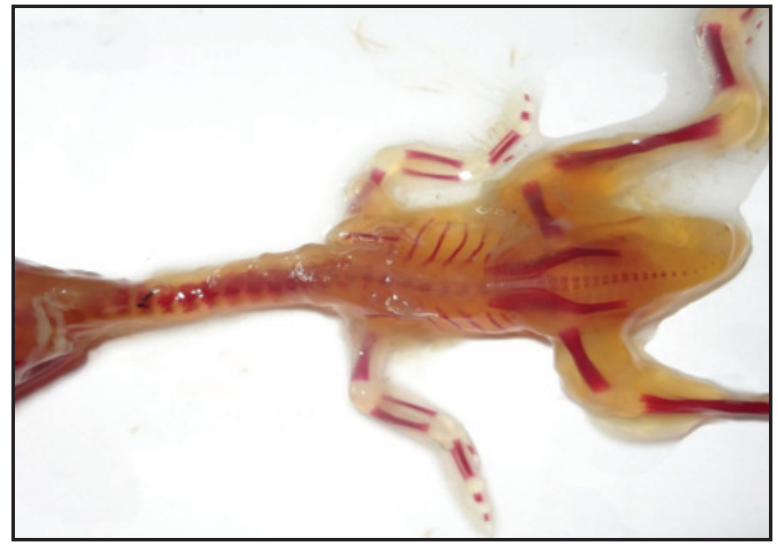

Fig. 11. Cervical, thoracic, lumbar, sacral and coccygeal vertebrates showing ossification ( $25^{\text {th }}$ day of incubation). Alizarin red staining.

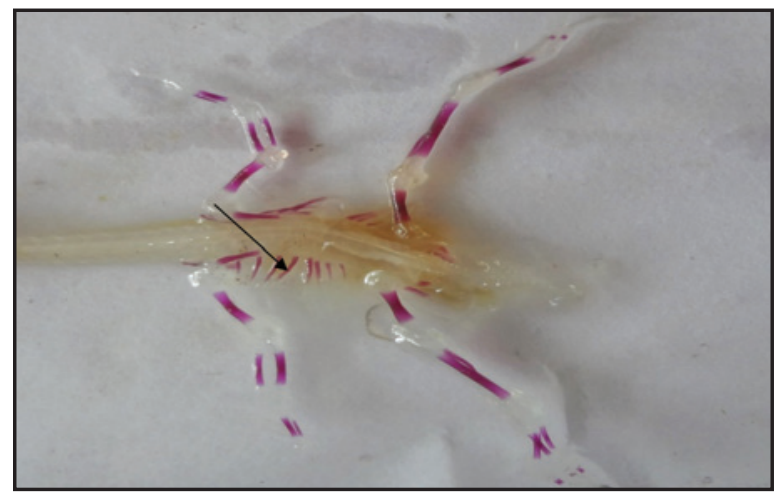

Fig. 12. Ossification of ribs ( $13^{\text {th }}$ day old embryo). Alizarin red staining. enzymatic clearing and staining or histological sections are used, and so studies using different methodologies are also comparable (Clark and Smith, 1993). In this regard, a pre-hatch developmental study of ossification sequences of axial and appendicular skeletal system in Kuttanad duck embryos was undertaken using 78 viable embryos.

The first indication of ossification in skull bones of Kuttanad duck embryos was seen as a small ossification centers and observed in squamosal bone on the $9^{\text {th }}$ day of incubation. In contradictory to quail as reported by Jollie (1957) the skull bones appeared on $11^{\text {th }}$ day of incubation. The wing ossified earlier as compared to the foot. Vasiliauskas et al. (2003) reported the same in hind limb of chicks but in disagreement to Zukiene et al. (2003) in mice. The ossification process of the forelimbs is in agreement

Table 2. The ossification of bones of Axial and Appendicular skeleton in Kuttanad duck embryos in given incubation period.

\begin{tabular}{lc}
\hline Structures ossified & $\begin{array}{c}\text { Time of ossification } \\
(\text { days })\end{array}$ \\
\hline Squamosal bone of skull & 9 \\
Palatine, pterygoid, prefrontal & 13 \\
Maxilla, Jugal, Quadratojugal, & 13 \\
Splenial, Angular, & \\
Supraangular, Premaxilla & \\
Clavicle & 9 \\
Scapula & 9 \\
Humerus & 9 \\
Radius & $9-13$ \\
Ulna & $9-13$ \\
Ilium & $9-11$ \\
Pubis & $9-11$ \\
Femur & $9-11$ \\
Fibula & 9 \\
Carpometacarpal joint & 13 \\
Ulnar carpal & 13 \\
Metatarsus & 13 \\
Tibiotarsus & 13 \\
First phalanx of digit ii & 13 \\
Second phalanx of digit iii & 13 \\
$4^{\text {th }}$ phalanx of digit ii of pelvic limb & 9 \\
Right and left clavicles & 17 \\
Vertebral arches of all the cervical, \\
thoracic, lumbar and sacral \\
vertebrates & \\
Pygostyle & \\
Ribs & 13 \\
\hline
\end{tabular}


to the studies of Saunder (1998) in forelimbs of chicks. Both clavicles were joined on $23^{\text {rd }}$ day of incubation but not properly fused. Ruchon et al. (1998) reported in mice the vertebrates ossified at the $16^{\text {th }}$ day, however, Lecanda et al. (2000) reported the process of vertebral ossification on the $15^{\text {th }}$ day of incubation. The ossification of the cervical vertebrate body in chick embryo started at the $12^{\text {th }}-13^{\text {th }}$ day of incubation while as sacral vertebrae get ossified on day $19^{\text {th }}$ of incubation (Shapiro, 1992).

Sawad et al. (2009) said that in Gallus the primary calcification of the rib body at the proximal extremity at the $10^{\text {th }}$ day of incubation. In case of chicken as reported by Hamburger and Hamilton (1951) the uncinate process calcifies directly. Nakane and Tsudzuki (1999) reported in quail that sternum ossification occurred in the laterocaudal process at the $14^{\text {th }}$ day of incubation and in the laterocranial process at the $15^{\text {th }}$ day of incubation.

\section{Conclusion}

In the present study, embryonic ossification sequences of skeletal system in Kuttanad duck were revealed. In this paper it is presumed that the stages of ossification of various elements of the body presented will be useful as a normal control in the fields of general embryology, developmental engineering, and teratological studies. The difference in the sequence of ossification of various skeletal elements in Kuttanad duck may be due to the appearance of ossification centers at different stages of incubation. Besides there was also a difference on comparative basis possibly due to the difference in the incubation period among different birds.

\section{Acknowledgments}

The authors highly acknowledge the Dean of faculty for providing the necessary facilities to carry out this work. The authors are grateful to the Department of Veterinary Physiology, Department of Veterinary Parasitology and Department of Veterinary Surgery and Radiology for providing the facilities.

\section{References}

Burdi, A.R. 1965. Toluidine Blue-Alizarin Red S Staining of Cartilage and Bone in Whole-Mount Skeletons in Vitro. Stain Technol. 40, 45-48.

Clark, C.T. and Smith, K.K. 1993. Cranial osteogenesis in Monodelphis domestica (Didelphidae) and Macropus eugenii (Macropodidae). J. Morphol. 215, 119-149.

Cook, M.E. 2000. Skeletal deformities and their causes: Introduction. Poult. Sci. 79, 982-984.

Hamburger, V. and Hamilton, H.L. 1951. A series of normal stages in the development of the chick embryo. J. Morphol. 88, 49-92.
Hogg, D.A. 1980. A reinvestigation of the centers of ossification in the avian skeleton at and after hatching. J. Anat. 130, 725-743.

Jollie, M.T. 1957. The head skeleton of the chicken and remarks on the anatomy of this region in other birds. J. Morphol. 100, 389-436.

Kerr, J.G. 1919. Textbook of Embryology. Vol 2. MacMillan. London.

Lecanda, F., Warlow, P.M., Sheikh, S., Furlan, F., Steinberg, T.H. and Civitelli, R. 2000. Connexin43 deficiency causes delayed ossification, craniofacial abnormalities, and osteoblast disfunction. J. Cell Biol. 151, 931-944.

Nakane, Y. and Tsudzuki, M. 1999. Development of the skeleton in Japanese quail embryos. Dev. Growth Differ. 41, 523-534.

Richardson, M.K., Hanken, J., Gooneratne, M.L., Pieau, C., Raynaud, A., Selwood L. and Wright, G.M. 1997. There is no highly conserved embryonic stage in vertebrates: implications for current theories of evolution and development. Anat. Embryol. 196, 91-106.

Ricklefs, R.E. and Starck, J.M. 1998. Embryonic growth and development. In: Avian Growth and Development. Evolution within the AltricialPrecocial. Academic Press, Oxford, pp: 31-58.

Rogulska, T. 1962. Differences in the process of ossification during the embryonic development of the chick (Gallus domesticus), rook (Corvus frugilegus) and black-headed gull (Larusridi bundus). Zool. Pol. 12, 223-236.

Ruchon, A.F., Marcinkiewicz, M., Siegfried, G., Tenenhouse, H.S., DesGroseillers, L., Crine, P. and Boileau, G. 1998. Pex mRNA is localized in developing mouse osteoblasts and odontoblasts. J. Histchem. Cytochem. 46, 459-468.

Saunder, J.W.Jr. 1998. The proximo-distal sequence of the origin of the parts of chick wing and the role of the ectoderm. J. Exp. Zool. 282, 628-668.

Sawad, A.A., Hana, B.A. and Al-Silawi, A.N. 2009. Morphological Study of the Skeleton Development in Chick Embryo (Gallus domesticus). Int. J. Poul. Sci. 8(7), 710-714.

Shapiro, F. 1992. Vertebral development of chick embryo during days 3-19 of incubation. J. Morphol. 213, 317-333.

Vasiliauskas, D., Laufer, E. and Stern, C.D. 2003. A role for hairy 1 in regulating chick Limb bud growth. Dev. Biol. 262, 94-106.

Zukiene, J., Zalgeviciene, V. and Rizgeliene, R. 2003. The influence of azathioprine on the osteogenesis of the limbs. Medicina 39, 584-588. 